\title{
Redhouse Kartlarındaki Türkçe Atasözleri Üzerine Bir Değerlendirme*
}

\section{An Evaluation of the Turkish Proverbs on the Redhouse Flash Cards}

\author{
Talat AYTAN*** Beste BİLGİÇ** (1)
}

"Bu makale, 11-12 Mayıs 2018 tarihinde İstanbul'da düzenlenen 1. Uluslararası Eğitimde Yeni Arayışlar Kongresi'nde sunulan aynı başlıklı sözlü bildirinin genişletilmiş hâlidir.

*Yıldız Teknik Üniversitesi, Eğitim Fakültesi, Türkçe Eğitimi Anabilim Dalı, İstanbul, Türkiye

ORCIDs: T.A. 0000-0001-9778-8970;

B.B. $0000-0001-5801-6636$

Sorumlu yazar/Corresponding author: Talat Aytan (Doç. Dr.),

Yıldız Teknik Üniversitesi, Eğitim Fakültesi, Türkçe Eğitimi Anabilim Dalı, İstanbul, Türkiye

E-posta: taytan@yildiz.edu.tr

Başvuru/Submitted: 12.06 .2020

Kabul/Accepted: 02.07.2020

Atıf/Citation: Aytan, T. \& Bilgiç, B. (2020).

Redhouse kartlarındaki türkçe atasözleri üzerine bir değerlendirme. Dilbilim Dergisi Journal of Linguistics, 35, 27-34.

https://doi.org/10.26650/jol.2020.008 öz

Türkçenin yabancı dil olarak öğretiminde dinleme, okuma, konuşma ve yazma becerilerinin geliştirilmesine ek olarak Türkçe gramer yapısının sezdirilmesi ve söz varlığının geliştirilmesi de hedeflenir. Söz varlığı bir dilde bulunan bütün dil göstergelerinin yekûnuna işaret eder. Söz varlığının en önemli bileşenlerinden biri de atasözleridir. Türkçeyi yabancı dil olarak öğrenenlerin Türk kültürünü anlayabilmesi için çeşitli kültür ögelerini barındıran atasözlerini kavraması da gerekmektedir. Bir dilin öğretiminde en asli unsurlardan birisi de ders kitaplarıdır. Ders kitaplarının yanı sıra flaş kart olarak tabir edilen kelime kartlarının sıklıkla kullanıldığı görülmektedir. Bu çalışmanın amacı Redhouse kartlarındaki 50 Türkçe atasözünü konulara göre tasnif ederek anlamlarına göre derecelendirmektir. Çalışmada Redhouse kartlarının, Türkçenin yabancı dil olarak öğretimi sahasında kullanılacağı varsayılmıştır. Gerçek ya da mecaz anlamlı atasözlerinin hangi kurlarda öğretilebileceği konusunda da önerilerde bulunulmuştur.

Anahtar kelimeler: Türkçenin yabancı dil olarak öğretimi, Redhouse Türkçe atasözleri kartları, Konu ve anlamı

\section{ABSTRACT}

When teaching Turkish as a foreign language, it is not only the development of the basic language skills of listening, reading, speaking and writing that should be emphasised but also the acquisition of correct grammar structures and vocabulary. Vocabulary refers to all of the language indicators in a language. One of the most important components of vocabulary is proverbs. In order to understand Turkish culture, it is also necessary to understand the proverbs that contain various cultural items. One of the most essential resources in teaching a language is the course book. In addition to course books, word cards, which are also called flash cards, are frequently used. The purpose of this study is to classify 50 Turkish proverbs on the Redhouse cards according to their topics and meanings. The study assumes that the Redhouse cards will be used in the area of teaching Turkish as a foreign language. In our study we also make some suggestions on how to teach the literal or metaphorical meanings of the proverbs according to language levels.

Keywords: Teaching Turkish as a foreign language, Redhouse Turkish proverbs cards, Topic and meaning 


\section{Giriş}

\subsection{Söz Varlı̆̆ı Kavramı}

Dil öğreniminde söz varlığının edinilmesi ve genişletilmesi büyük önem arz etmektedir. Söz varlığı, bir dilin bütün kelimeleri; bir kişinin veya toplumun söz dağarcı̆̆ında olan kelimeler toplamıdır (Korkmaz, 1992:140). İngilizcede vocabulary, Fransızcada vocabulaire, Almancada Wortschatz olan söz varlığı kavramı, TDK Türkçe Sözlük’te "sözlerin bütünü, söz hazinesi, söz dağarcığı, sözcük hazinesi, kelime hazinesi, kelime kadrosu, vokabüler” olarak geçmektedir. Söz varlığı, bir dile ait tarihsel ve eşzamanlı anlamlarının tamamını karşılar ve o dilde üretilmiş tüm anlam birimlerini kapsar (Karadağ, 2013). Aksan (2006)'a göre Türkçe söz varlığının soyut- somut isimler, eylemler, terimler, ikilemeler, kalıp sözler, deyimler, atasözlerinden oluşan geniş bir yelpazesi bulunmaktadır.

\subsection{Atasözü Kavramı}

Atasözleri, söz varlığının önemli bir bölümünü oluşturur. Atasözleri gerek sözlerindeki vurucu etkisi gerekse toplumun kültürünü yansıtması bakımından derin bir hazine olarak karşımıza çıkar. Atasözleri, Türkçenin kıvraklığını ve güzelliğini yansıtan, dilden dile aktarılagelen özlü sözlerdir. Söyleyiş ve anlatım olarak çok güçlüdür. İlham değil deneyimlerin sonucudur. Toplumun onayından, zamanın süzgecinden geçmiştir (Sertel, 2006). Atasözleri, atalarımızın uzun denemelere dayanan yargılarını genel kural, bilgece düşünce ya da öğüt olarak düsturlaştıran, kalıplaşmış biçimleri bulunan ve kamuca benimsenmiş olan özlü sözlerdir (Aksoy,1988). Atasözleri, ele aldıkları konular bakımından çok çeşitlilik gösterir. Her ulusun bir karakteri vardır (Oy, 1972). Bu bağlamda her ulus gelenekleri ve aldığı kültür çerçevesinde dünya görüşlerini dışa vurur. Yurtbaşı (2013), Türk atasözlerini 172 konuda toplamıştır. Bu konulardan bazıları şunlardır: acelecilik, aç gözlülük, adalet, aşk, azim, bağışlama, başarı, bilgi, cimrilik, çalışkanlık, çocuk, din, dost, dünya, eğitim, evlilik, gurur, güven, hayat, iklim, iyilik, kadın, komşu, kurnazlık, mutluluk, nankörlük, öfke, ölçülülük, ölüm, sabır, sağlık, tarım, ticaret, yalnızlık, yardım, zenginlik, zulüm...

\subsection{Yabancı Dil Olarak Türkçe Öğretiminde Atasözlerinin Öğretimi}

Atasözleri metafor içeren bir yapıya sahiptir. Metafor, çoğu insan için retorik bir gösteriş hilesidir. Metafor, gündelik hayatta sadece dilde değil düşünce ve eylemde de yaygındır (Lakoff, Johnson, 2005). Atasözlerinin düşünce, eylem ve deneyimlerden ortaya çıktığg düşünüldügüünde önemli metaforlardan olduğu söylenebilir.

Tekin (2019), deyim ve atasözlerinin öğretim stratejileri konulu çalışmasında figüratif dil üzerinde durmuştur. Figüratif dil içerisinde, metaforlar, benzetmeler, kişileştirme, mübalağa, kinaye, atasözü ve deyimler (Prambling, 2016) gibi unsurların bulunduğu belirtilir. Figüratif dilde kastedilen anlam gerçek anlamla örtüşmediği için figüratif dil özellikle yabancı dil öğrenenler açısından zor anlaşılmaktadır. Bu durumda atasözü ve deyimlerin öğretiminin 
öğretilen ve öğrenilen dilde açıklanması önemlidir. Başka dillere direkt çeviri yerine Türkçedeki atasözü ve deyimlerin bağlama, görsellere, örneklere, açıklamalara başvurularak çeşitli yollarla öğrencilere aktarılması uygun olabilir (Tekin, 2019).

Akpınar (2010) deyim ve atasözlerinin yabancılara Türkçe öğretiminde kullanımı konulu çalışmasında, dili öğrenen kişinin o dili kullanan toplumun kültürünü de öğrendiğini belirtmektedir. Atasözü ve deyimlerin oluşumunda kültürün etkin rol oynadığı düşünülürse atasözü ve deyim kullanımının önemi ortaya çıkar. Ne var ki yabancı dil öğretiminde atasözünün hangi öğretim basamağında ve nasıl kullanılabileceği konusu tartışmalı bir konudur. Akpınar'a göre atasözleri; okuma, dinleme metinlerinde mutlaka bulunmalı, konuşma ve yazma çalışmalarında öğrencilerin öğrendiklerini kullanması sağlanmalıdır. Atasözü ve deyimlerin öğretiminde basitten karmaşığa, somuttan soyuta giden bir yol izlenmelidir. Sadece ders kitabına bağlı kalınmayıp ek materyallerden yararlanılmalıdır (Akpınar, 2010).

Çeçen (2007) araştırmasında atasözlerinin dört basamakta öğretilmesini uygun görmüştür. 1.basamakta görünüşteki anlamıyla bir mesaj taşıyan, göndergelerin açık olarak ifade edildiği atasözlerine yer verilmiştir. Bu atasözlerinin yalnızca yüzey yapısı vardır. Söylenenin dışında bir anlam aramaya gerek yoktur:" Yazın başı pişenin kışın aşı pişer. İyi dost kötü günde belli olur... vb." 2. basamakta gösterge olarak belli bir anlamı ve mesajı olmakla birlikte açık olarak ifade edilmeyen mesajların da bulunduğu atasözlerine yer verilmiştir. Atasözlerinin hem yüzey hem de derin yapısı vardır: "Sakla samanı gelir zamanı. Lafla peynir gemisi yürümez. Ne ekersen onu biçersin. Perşembenin gelişi çarşambadan belli olur. Damlaya damlaya göl olur. Sütten ağzı yanan, yoğurdu üfleyerek yer. Bir elin nesi var, iki elin sesi var. ... vb.” 3.basamakta benzetme gibi söz sanatlarıyla yapılmış, somut ve mecaz ifadeler taşıyan, derin yapıdaki atasözlerine yer verilmiştir: "Üzüm üzüme baka baka kararır...vb” 4.basamakta ise Türk toplumuna has değerleri ve kültür unsurlarını barındıran anlayışların, kavram ve ifadelerin bulunduğu atasözlerine yer verilmiştir. Bu atasözleri, derin yapının kültürel unsurlar ve değerler şeklinde ortaya çıktığı sözlerdir:" Misafir kısmetiyle gelir... vb.” toplumun kültürünü iyice tanıyan birinin anlayabileceği atasözlerinin ise en son öğretilmesi gerektiği düşünülebilir.

\section{Yöntem}

Bu çalışmanın veri toplama kısmında doküman incelemesi yöntemi kullanılmıştır. Doküman incelemesi yönteminde amaç, araştırılması hedeflenen olgu ya da olgular hakkında bilgi içeren yazılı materyallerin analizidir. Hangi dokümanların önemli olduğu ve veri kaynağı olarak kullanılabileceği araştırma problemiyle ilgilidir (Yıldırım ve Şimşek, 2016: 189). Dokümanlar veri kaynağı olarak kullanılabilir. Bu çalışmada Redhouse Atasözü Kartları (Çeküç, 2016) isimli materyal, tek başına bir veri kaynağı olarak kullanılmıştır. Dokümanın yorumlanmasında ise içerik analizi yöntemi uygulanmıştır. 'İçerik analizinde temel amaç, toplanan verileri açıklayabilecek kavramlara ve ilişkilere ulaşmaktır. Toplanan verilerin önce kavramsallaştırılması, ortaya çıkan kavramlara göre mantıklı bir biçimde düzenlenmesi ve 
veriyi açıklayan temaların saptanması gerekir' (Yıldırım ve Şimşek, 2016: 242). Bu çalışmada kartlardaki atasözlerinden oluşan veriler, anlamsal ve tematik olarak kodlanmıştır. Tematik ve anlamsal olarak birbiriyle aynı olan atasözleri aynı sınıfa dâhil edilmiştir. Daha sonra konuların kullanım sıklığı hesaplanmış ve elde edilen nitel veriler, yüzdelere indirgenmiştir.

\section{Bulgular ve Yorum}

\subsection{Redhouse Türkçe Atasözü Kartlarında Ele Alınan Konuların Tasnifi}

Söz varlığı içerisinde kalıp sözler ya da ilişki sözleri genellikle deyimsel bir anlam ifade eder. Söz varlığının en önemli bileşenlerinden biri de atasözleridir. Atasözleri âlemşümul hakikatleri, hikmet ve marifet tohumlarını bünyesinde bulundurur. Atasözleri bir milletin çağlar boyunca tecrübeyle sabitlenmiş değer yargılarının toplamını ifade eder. Başka bir deyişle atasözleri, bir milletin dünyayı algılama ve kavrama biçiminin bir tezahürüdür. Bilindiği üzere dil öğretimi aynı zamanda bir kültür ve değer aktarımıdır. Türkçeyi yabancı dil olarak öğrenenlerin Türk kültürünü ve medeniyet tasavvurunu alımlayabilmesi için dil öğretimi bir firsatlar manzumesi sunmaktadır. Atasözlerinin öğretiminde hedef dil ile kaynak dilde aynı anlama gelen atasözlerinden ve gerçek anlamlı atasözlerinden başlanılması, orta ve ileri seviyede atasözlerinin öğretim materyallerinde yoğun olarak kullanılması genel bir kabul görmektedir.

Tablo-1'de, Redhouse kartlarındaki Türkçe atasözlerinin tematik olarak tasnifi gösterilmiştir. Redhouse Türkçe Atasözleri kartlarındaki 50 atasözü, 33 konu başlığı altında toplanmıştır. Aşikârlık, bozukluk/bozulma, eğitim, emek ve çalışma, fedakârlık, rekabet, sonuç, sorumluluk, tedbirli olma, tutumluluk ve yardımlaşmanın en sık kullanılan konu başlıkları olduğu tespit edilmiştir.

Tablo 1: Redhouse Kartlarındaki Türkçe Atasözlerinin Tematik Tasnifi

\begin{tabular}{|l|l|l|}
\hline Sıklık & Konu & Atasözü \\
\hline 1 & ACELECILIK & Aceleci sinek süte düşer. \\
\hline 1 & ALIŞKANLIKLAR & $\begin{array}{l}\text { Tilkinin dönüp dolaşacağı yer kürkçü } \\
\text { dükkânıdır. }\end{array}$ \\
\hline 2 & AŞiKÂRLIK & $\begin{array}{l}\text { Görünen köy kılavuz istemez. } \\
\text { Perşembe'nin gelişi çarşambadan bellidir. }\end{array}$ \\
\hline 1 & BOŞUNALIK & Çürük tahta çivi tutmaz. \\
\hline 2 & BOZUKLUK/ BOZULMA & $\begin{array}{l}\text { Balık baştan kokar. } \\
\text { Üzüm üzüme baka baka kararır. }\end{array}$ \\
\hline 1 & ÇARESIZLIK & Denize düşen yılana sarılır. \\
\hline 1 & DOSTLUK/ARKADAŞLIK & Dost kara günde belli olur. \\
\hline 2 & EĞiTíM & $\begin{array}{l}\text { Ağaç yaşken eğilir. } \\
\text { Boynuz kulağ1 geçer. }\end{array}$ \\
\hline
\end{tabular}




\begin{tabular}{|c|c|c|}
\hline 5 & EMEK / ÇALIŞMA & $\begin{array}{l}\text { Emek olmadan yemek olmaz. } \\
\text { İşleyen demir ışıldar. } \\
\text { Lafla peynir gemisi yürümez. } \\
\text { Taşıma su ile değirmen dönmez. } \\
\text { Yazın başı pişenin, kışın aşı pişer. }\end{array}$ \\
\hline 1 & EMPATİ & Gülme komşuna gelir başına. \\
\hline 2 & FEDAKÂRLIK & $\begin{array}{l}\text { Gülü seven dikenine katlanır. } \\
\text { Kaz gelen yerden tavuk esirgenmez. }\end{array}$ \\
\hline 1 & FIRSATLARI DEĞERLENDİRME & Kaçan balık büyük olur. \\
\hline 1 & GERÇEKLIK & Güneş balçıkla sıvanmaz. \\
\hline 1 & GEZİ / DENEYİM & Çok gezen çok bilir. \\
\hline 1 & GÖRÜNÜŞE ALDANMA & Davulun sesi uzaktan hoş gelir. \\
\hline 1 & HAZIRLIKSIZ OLMA & Ummadığın taş baş yarar. \\
\hline 1 & ÍLETISŞIMSİZLIK & Gözden rrak olan, gönülden de rrak olur. \\
\hline 1 & KAZANÇ & Zararın neresinden dönülürse kardır. \\
\hline 1 & KISMET & İyi olacak hastanın hekim ayağına gelir. \\
\hline 1 & KOMŞULUK & Komşu komşunun külüne muhtaçtır. \\
\hline 1 & KONUKSEVERLIK & Misafir kısmeti ile gelir. \\
\hline 1 & ÖFKENIN ZARARI & Öfkeyle kalkan zararla oturur. \\
\hline 1 & PAYLAŞIM & Biri yer biri bakar, kıyamet ondan kopar. \\
\hline 2 & REKABET & $\begin{array}{l}\text { İki cambaz bir ipte oynamaz. } \\
\text { İki testi tokuşunca biri elbet kırılır. }\end{array}$ \\
\hline 1 & SAĞLIK & Güneş girmeyen eve doktor girer. \\
\hline 2 & SONUÇ & $\begin{array}{l}\text { İp inceldiği yerden kopar. } \\
\text { Ne ekersen onu biçersin. }\end{array}$ \\
\hline 2 & SORUMLULUK & $\begin{array}{l}\text { Bakarsan bağ, bakmazsan dağ olur. } \\
\text { Her koyun kendi bacağından asılır. }\end{array}$ \\
\hline 3 & TEDBİRLİ OLMA & $\begin{array}{l}\text { Dere geçerken at değiştirilmez. } \\
\text { Mart kapıdan baktırır kazma kürek yaktırır. } \\
\text { Sütten ağzı yanan yoğurdu üfleyerek yer. }\end{array}$ \\
\hline 1 & TEMIZLİK & Aslan yattığ1 yerden belli olur. \\
\hline 4 & TUTUMLULUK & $\begin{array}{l}\text { Ak akçe kara gün içindir. } \\
\text { Ayağını yorganına göre uzat. } \\
\text { Damlaya damlaya göl olur. } \\
\text { Sakla samanı gelir zamanı. }\end{array}$ \\
\hline 1 & UMUT & Gün doğmadan neler doğar. \\
\hline 2 & YARDIMLAŞMA & $\begin{array}{l}\text { Bir elin nesi var, iki elin sesi var. } \\
\text { Terzi kendi söküğünü dikemez. }\end{array}$ \\
\hline 1 & ZAMAN YÖNETIMI & Bir koltuğa iki karpuz sığmaz. \\
\hline
\end{tabular}

\subsection{Redhouse Kartlarındaki Konu Dăğlım Yüzdesi}

Tablo-1'deki konuların kullanım sıklığına göre en sık rastlanan konu başlıkları yüzdeliklerinin şu şekilde olduğu görülmektedir:

Aşikârlık: \%4

Bozukluk/ Bozulma: \%4

Eğitim: \%4

Emek ve çalışma: \%10 
Fedakârlık: \%4

Rekabet: \%4

Sonuç: \%4

Sorumluluk: $\% 4$

Tedbirli olma: $\% 6$

Tutumluluk: $\% 8$

Yardımlaşma: \%4

Görüldüğü üzere kültür aktarımı sağlayacak olan atasözleri, milletçe önemsediğimiz değerleri barındırmaktadır.

Tablo-2'de, Redhouse kartlarındaki Türkçe atasözlerinin anlamsal olarak tasnifi gösterilmiştir. Redhouse Türkçe Atasözleri kartlarındaki 50 atasözünün, 12'sinin gerçek anlamlı; 38'inin ise mecaz anlamlı olduğu tespit edilmiştir.

\subsection{Redhouse Kartlarındaki Türkçe Atasözlerinin Anlamsal Tasnifi}

Tablo 2: Redhouse Kartlarındaki Türkçe Atasözlerinin Anlamsal Tasnifi

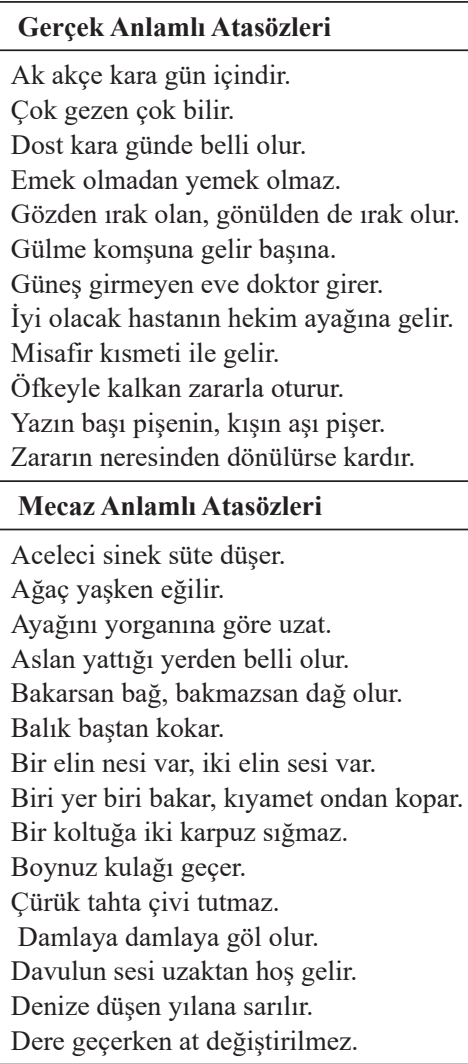




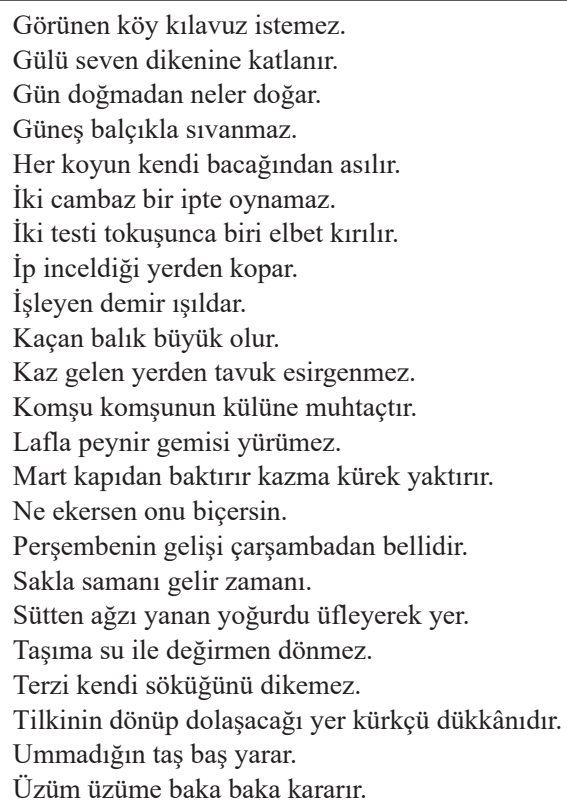

Bu bağlamda, Redhouse Türkçe Atasözleri kartlarındaki 50 atasözünün; \%24’ü gerçek anlamlı, \%76'sı mecaz anlamlıdır.

\section{Sonuç ve Değerlendirme}

Atasözlerinin önce ünitelere, temalara göre sınıflandırılması (sağlık, aile, sanat, ticaret, iletişim... vb.), sonrasında somut-soyut, mecaz-gerçek anlama göre bir tasnif edilmesi, son olarak da dil bilgisi konularına göre kategorize edilmesi atasözlerinin Türkçenin yabancı dil olarak öğretiminde ehemmiyet arz etmektedir. Atasözlerinin öğretiminde her ulusta bulunan ortak değerleri içeren atasözlerine, olumlanan-olumsuzlanan insan davranışlarına yönelik olanlarına öncelik verilmelidir (Akpınar,2010). Tekin (2019)'e göre atasözlerinin anlamını çağrıştıracak görsellere yer verilmesi düz anlatımdan daha güçlü bir etki yaratır. Görseller hafızaya yardımcı olabilir ve atasözlerinin kalıcı olarak öğrenilmesine zemin hazırlar. Atasözleri öğretilirken bağlamdan yola çıkılmalıdır ve imgesel kelimeler somutlaştırılarak anlatılmalıdır. ‘'Öğrencilerin gerçek hayatta karşılaşma ihtimali yüksek olan atasözlerinin öğretimine öncelik verilmelidir" (Karadağ, 2013).

50 atasözü ile sınırlı olan bu araştırmada, tasnif gerçek ve mecaz anlamlı olmak üzere iki kısımda yapılmıştır. Çalışmanın konu tasnifi bölümünde millî değerlerimiz olan çalışma, tasarruf yapma, komşuluk, yardımlaşma gibi temaların sık kullanıldığı görülmektedir. Sık kullanılan değerler konulu atasözlerimizin kültürün aktarımı açısından önce verilmesi yerinde olacaktır. Düz anlatımın söz konusu olduğu gerçek anlamlı atasözleri, derin yapı ya da sembolize 
edilmiş kullanım içermediği için bu atasözlerinin anlaşılması kolaydır. Bu bağlamda kartlarda bulunan 12 gerçek anlamlı atasözünün A2 başlangıç düzeyinde öğretilmesinin ve geriye kalan 32 atasözünün ise orta ve ileri seviyelerde öğretilmesinin uygun olacağı ön görülmektedir.

Redhouse Atasözü Kartları 'nın; gerek atasözünü resimleyen görsel yapısı, gerek bağlamı sezdirmeye yönelik olarak bir hikâye içinde verilmesi, gerekse günlük hayatta sık karşımıza çıkan atasözlerinden derlenmiş olmasıyla oldukça işlevsel, kullanışlı ve öğrenmeye güdüleyici bir materyal olduğu söylenebilir. Bu materyalin Türkçenin yabancı dil olarak öğretiminde atasözlerinin öğretilmesine yardımcı olacağı düşünülmektedir.

\footnotetext{
Hakem Değerlendirmesi: Dış bağımsız.

Çıkar Çatışması: Yazarlar çıkar çatışması bildirmemiştir.

Finansal Destek: Yazarlar bu çalışma için finansal destek almadığını beyan etmiştir.

Peer-review: Externally peer-reviewed.

Conflict of Interest: The authors have no conflict of interest to declare.

Grant Support: The authors declared that this study has received no financial support.
}

\section{Kaynakça/References}

Aksan, D. (2006). Ana Dilimizin Söz Denizinde. İstanbul: Bilgi Yayınevi.

Akpınar, M. (2010). Deyim ve Atasözlerinin Yabancılara Türkçe Öğretiminde Kullanımı Üzerine Bir Araştırma. Yayımlanmamış Yüksek Lisans Tezi. Gazi Üniversitesi Eğitim Bilimleri Enstitüsü.

Aksoy, Ö. A. (1988). Atasözler ve Deyimler Sözlüğ̈̈ I-II. İstanbul: İnkılap Kitapevi.

Çeçen, M.A. Yabancılara Türk Atasözlerinin Öğretiminde Slralamaya İlişkin Bir Deneme. Türkiye'de Yabancı

Dil Eğitimi Ulusal Kongresi, 22-23 Kasım 2007.

Çeküç, B.Ü. (Ed.). (2016). Redhouse Atasözleri Kartları. İstanbul: Sev Yayıncılık

Karadağ, Özay. (2013). Kelime Öğretimi. İstanbul: Kriter Yayınevi.

Lakoff, G. \& Mark, J. (2015). Metaforlar Hayat, Anlam ve Dil. (Çev. Gökhan Yavuz Demir). İstanbul: Paradigma Yayınc1lık.

Oy, A. (1972). Tarih Boyunca Türk Atasözleri. İstanbul: Türkiye İş Bankası Kültür Yayınları.

Sertel, A. (2006). Tecrübelerin Dili Konulu Atasözleri. İstanbul: Pozitif Yayıncılık.

Tekin, E. (2019). Yabancı Dil Olarak Türkçe Öğretimi Kitaplarında Atasözü ve Deyimlerin Öğretim Stratejileri Üzerine Bir Durum Tespiti. Yayımlanmamış Yüksek Lisans Tezi. Yıldız Teknik Üniversitesi Sosyal Bilimler Enstitüsü.

Yurtbaşı, M. (2013). Sinıflandırılmış Türk Atasözleri. İstanbul: Excellence Yayıncılık. 